Pediatrics

\title{
Exploring the use of adjusted body mass index thresholds based on equivalent insulin resistance for defining overweight and obesity in UK South Asian children
}

\author{
Mohammed T. Hudda $\mathbb{D}^{1} \cdot$ Angela S. Donin ${ }^{1} \cdot$ Christopher G. Owen $^{1} \cdot$ Alicja R. Rudnicka $^{1} \cdot$ Naveed Sattar $^{2}$. \\ Derek G. Cook ${ }^{1}$ Peter H. Whincup ${ }^{1}$ - Claire M. Nightingale ${ }^{1}$
}

Received: 4 July 2018 / Revised: 12 October 2018 / Accepted: 4 November 2018 / Published online: 13 December 2018

(c) The Author(s) 2018. This article is published with open access

\begin{abstract}
Background Body mass index (BMI) overweight/obesity thresholds in South Asian (SA) adults, at equivalent type-2 diabetes risk are lower than for white Europeans (WE). We aimed to define adjusted overweight/obesity thresholds for UKSA children based on equivalent insulin resistance (HOMA-IR) to WE children.

Methods In $1138 \mathrm{WE}$ and 1292 SA children aged 9.0-10.9 years, multi-level regression models quantified associations between BMI and HOMA-IR by ethnic group. HOMA-IR levels for WE children were calculated at established overweight/ obesity thresholds (at 9.5 years and 10.5 years), based on UK90 BMI cut-offs. Quantified associations in SA children were then used to estimate adjusted SA weight-status thresholds at the calculated HOMA-IR levels.

Results At 9.5 years, current WE BMI overweight and obesity thresholds were $19.2 \mathrm{~kg} / \mathrm{m}^{2}, 21.3 \mathrm{~kg} / \mathrm{m}^{2}$ (boys) and $20.0 \mathrm{~kg} / \mathrm{m}^{2}$, $22.5 \mathrm{~kg} / \mathrm{m}^{2}$ (girls). At equivalent HOMA-IR, SA overweight and obesity thresholds were lower by $2.9 \mathrm{~kg} / \mathrm{m}^{2}(95 \%$ CI: $2.5-3.3 \mathrm{~kg} / \mathrm{m}^{2}$ ) and $3.2 \mathrm{~kg} / \mathrm{m}^{2}\left(95 \%\right.$ CI: $2.7-3.6 \mathrm{~kg} / \mathrm{m}^{2}$ ) in boys and $3.0 \mathrm{~kg} / \mathrm{m}^{2}\left(95 \%\right.$ CI: $\left.2.6-3.4 \mathrm{~kg} / \mathrm{m}^{2}\right)$ and $3.3 \mathrm{~kg} / \mathrm{m}^{2}$ (95\% CI: $2.8-3.8 \mathrm{~kg} / \mathrm{m}^{2}$ ) in girls, respectively. At these lower thresholds, overweight/obesity prevalences in SA children were approximately doubled (boys: $61 \%$, girls: $56 \%$ ). Patterns at 10.5 years were similar.

Conclusions SA adjusted overweight/obesity thresholds based on equivalent IR were markedly lower than BMI thresholds for WE children, and defined more than half of SA children as overweight/obese.
\end{abstract}

\section{Introduction}

Body mass index (BMI), the most widely used method for assessing adiposity, underestimates total body fat (BF) in

Supplementary information The online version of this article (https:// doi.org/10.1038/s41366-018-0279-7) contains supplementary material, which is available to authorized users.

Mohammed T. Hudda

mhudda@sgul.ac.uk

$\bowtie$ Peter H. Whincup

pwhincup@sgul.ac.uk

$\triangle$ Claire M. Nightingale cnightin@sgul.ac.uk

1 Population Health Research Institute, St George's, University of London, London, UK

2 Institute of Cardiovascular and Medical Sciences, University of Glasgow, Scotland, UK
South Asian (SA) people [1]. Several UK studies have shown that at equivalent type-2 diabetes (T2D) risk, BMI levels are markedly lower in SA adults compared to white European (WE) adults [2-4], suggesting that BMI thresholds for defining overweight and obesity in SA adults should be lower than those for WEs [1-5]. However, no equivalent thresholds have been developed in children. Although BMI thresholds based on equivalent T2D risks would be difficult to quantify in children, an alternative would be to use equivalent levels of insulin resistance, a strong and consistent precursor of T2D risk both in adults $[6,7]$ and in children [8], in whom consistent ethnic differences are observed [9]. Here we explore the use of this approach to estimate adjusted BMI thresholds for defining overweight and obesity in UK-SA children.

\section{Research design and methods}

In the Child Heart and Health Study England (CHASE), a school-based study of 9.0-10.9 year UK children of 
different ethnic origins [9] conducted between 2004 and 2007, height was measured with a portable stadiometer (Chasmors Ltd, London, UK) and weight with an electronic digital scale (Tanita Inc, Tokyo, Japan). Female pubertal status was assessed using Tanner breast development staging [10]. Participant ethnicity was defined using the ethnicity of both parents or if not available, parentally-defined child ethnicity. Serum insulin and plasma glucose were measured in fasting blood samples [9], allowing Homeostasis Model Assessment insulin resistance [11] (HOMAIR) to be determined.

Statistical analyses were performed using Stata v14. HOMAIR was positively skewed and log transformed (natural log transformation) for analysis. Multi-level regression models were fitted using the residual maximum likelihood approach to assess the associations between log HOMA-IR (dependent variable) and BMI in both ethnic groups for both boys and girls. Models were adjusted for age (continuous), sex, ethnic group and month of measurement (fixed effects) with a random effect to allow for clustering of children at school level. Two-way interaction terms between BMI and both sex and ethnicity were tested using the Wald test at the 5\% significant level. A statistically significant interaction was detected between BMI and ethnic group $\left(\mathrm{P}_{\text {interaction }}=0.01\right)$, which was included in the model as a fixed effect. Standardised residual plots were used to assess the model fit.

To determine adjusted BMI thresholds for SA children, we obtained sex-specific thresholds for overweight and obesity in WEs from UK90 growth charts [12]. The coefficients from the multi-level regression models (described above) were used to estimate levels of HOMA-IR in WEs at the UK90 overweight and obesity threshold levels. The same regression model coefficients were then rearranged to estimate BMI levels in SAs corresponding to the same HOMA-IR values. This process was embedded within a bootstrapping procedure to obtain $95 \%$ bootstrap confidence intervals $(95 \% \mathrm{BCI})$ for these estimates (described in the Appendix).

\section{Results}

In all, 2430 children (49.7\% boys) aged 9-10 years without diabetes provided complete data, including $1138 \mathrm{WE}$ and 1292 SA children. Characteristics of the analysis sample are summarised in Supplementary Table 1. WE children were on average taller and heavier than their SA counterparts but had lower HOMA-IR levels (Supplementary Table 1).

\section{Associations between BMI and log HOMA-IR}

After adjusting for age, sex and month of measurement, each $1 \mathrm{~kg} / \mathrm{m}^{2}$ increase in BMI was associated with a $9.2 \%$
(95\% CI: 8.2-10.1\%) increase in HOMA-IR in WE and a $10.8 \%$ (95\% CI: $10.0-11.7 \%)$ increase in SA children. Histograms and normal plots of the standardised residuals from the regression models did not show any departures from normality, and there was no evidence of residual curvature when standardised residuals were plotted against fitted values.

\section{BMI thresholds for overweight and obesity in SA children at equivalent HOMA-IR}

\section{Nine-year-olds (central age 9.5 years)}

Current overweight and obesity thresholds for WE boys are $19.2 \mathrm{~kg} / \mathrm{m}^{2}$ and $21.3 \mathrm{~kg} / \mathrm{m}^{2}$, respectively. The equivalent HOMA-IR levels corresponding to these thresholds were 0.8 and 0.9 , respectively. At these HOMA-IR levels, overweight and obesity thresholds for SA boys were lower by $2.9 \mathrm{~kg} / \mathrm{m}^{2}\left(95 \%\right.$ BCI: $\left.2.5-3.3 \mathrm{~kg} / \mathrm{m}^{2}\right)$ and $3.2 \mathrm{~kg} / \mathrm{m}^{2}$ (95\% BCI: $2.7-3.6 \mathrm{~kg} / \mathrm{m}^{2}$ ), respectively (Fig. 1 \& Supplementary Table 2). Overweight and obesity thresholds for WE girls are $20.0 \mathrm{~kg} / \mathrm{m}^{2}$ and $22.5 \mathrm{~kg} / \mathrm{m}^{2}$, respectively. Equivalent levels of HOMA-IR were 1.0 and 1.2; corresponding overweight and obesity thresholds for SA girls were lower by $3.0 \mathrm{~kg} / \mathrm{m}^{2}$ (95\% BCI: $\left.2.6-3.4 \mathrm{~kg} / \mathrm{m}^{2}\right)$ and $3.3 \mathrm{~kg} / \mathrm{m}^{2}$ (95\% BCI: $2.8-3.8 \mathrm{~kg} / \mathrm{m}^{2}$ ), respectively (Fig. $1 \&$ Supplementary Table 2).

\section{Ten-year-olds (central age 10.5 years)}

Current overweight and obesity thresholds for WE boys are $19.8 \mathrm{~kg} / \mathrm{m}^{2}$ and $22.2 \mathrm{~kg} / \mathrm{m}^{2}$, respectively and for girls are $20.8 \mathrm{~kg} / \mathrm{m}^{2}$ and $23.4 \mathrm{~kg} / \mathrm{m}^{2}$, respectively. At equivalent HOMA-IR levels, overweight and obesity thresholds for SA boys were lower by $3.0 \mathrm{~kg} / \mathrm{m}^{2}$ (95\% BCI: $\left.2.5-3.4 \mathrm{~kg} / \mathrm{m}^{2}\right)$ and $3.3 \mathrm{~kg} / \mathrm{m}^{2}$ (95\% BCI: $2.8-3.8 \mathrm{~kg} / \mathrm{m}^{2}$ ), respectively and for SA girls were lower by $3.1 \mathrm{~kg} / \mathrm{m}^{2}$ (95\% BCI: $2.7-3.6 \mathrm{~kg} / \mathrm{m}^{2}$ ) and $3.5 \mathrm{~kg} / \mathrm{m}^{2}$ (95\% BCI: $\left.2.9-4.0 \mathrm{~kg} / \mathrm{m}^{2}\right)$, respectively (Fig. $1 \&$ Supplementary Table 2).

Among SA children, the prevalences of overweight and obesity using the adjusted BMI thresholds increased markedly, so that more than half of both 9 and 10 year old SAs were classified as overweight or obese, compared with between a quarter and a third using conventional BMI thresholds (Supplementary Table 3). The exclusion of girls with evidence of pubertal development did not materially affect these results.

\section{Conclusions}

This study quantified ethnic differences in the associations between childhood BMI and HOMA-IR (a precursor of 

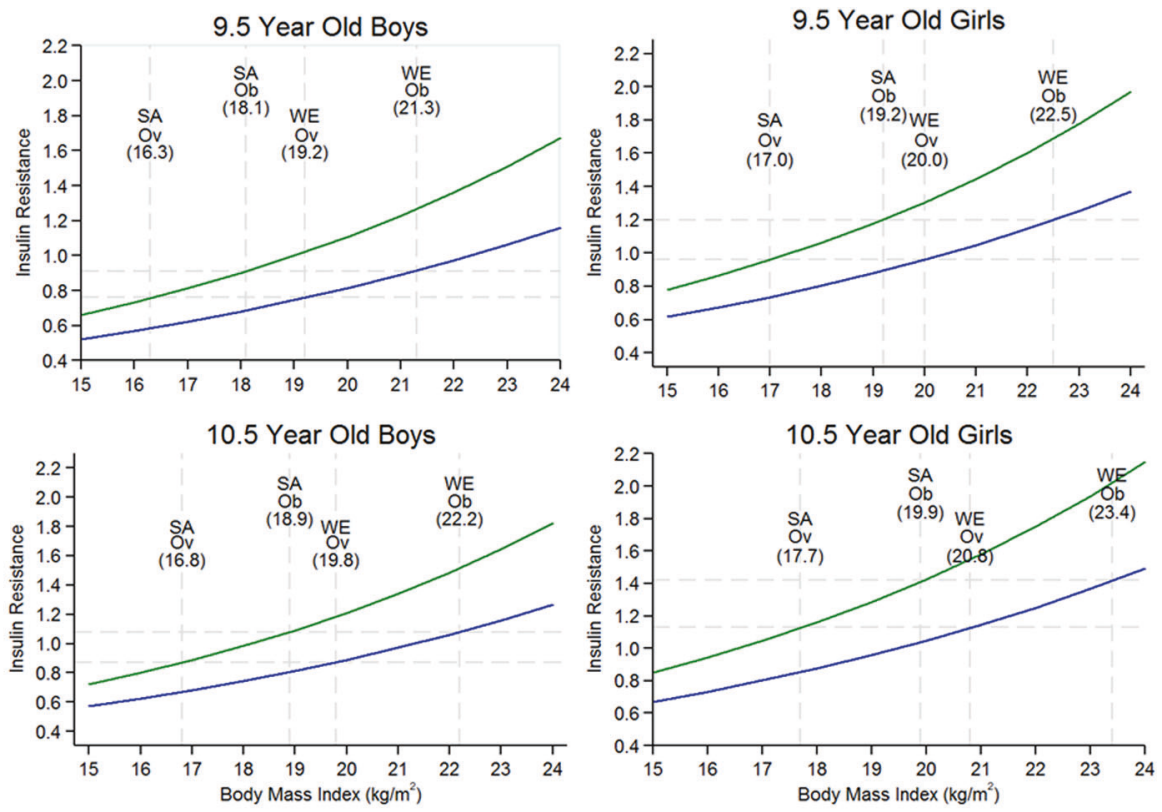

FOOTNOTE: $\mathrm{SA}=$ South Asians $\mathrm{WE}=$ White Europeans $\mathrm{Ov}=$ Overweight $\mathrm{Ob}=$ Obese. The relationship between BMI and Insulin Resistance are shown in blue for White Europeans and in green for South Asians. Dotted vertical lines labelled WE Ov and WE Ob represent the UK90 thresholds for overweight (ov) and obesity (ob) $\left(\mathrm{kg} / \mathrm{m}^{2}\right)$ for the age-sex groups for white European children and also the equivalent newly derived thresholds for South Asian children (SA Ov and SA Ob). Horizontal lines represent the equivalent level of Insulin

Resistance from the regression models at the overweight and obesity thresholds.

Fig. 1 Associations between BMI and HOMA insulin resistance, showing adjusted BMI thresholds for overweight and obesity in South Asian Boys (left) and girls (right) aged 9.5 (top) and 10.5 (bottom) years based on equivalent HOMA-Insulin Resistance levels in White Europeans

aged 9-10 years identified as overweight or obese. These findings emphasize the major population health challenge represented by overweight, obesity and T2D in the UK-SA population. Although individually based identification and management of overweight and obese children could play a role in prevention, focussed population-wide strategies for controlling weight gain in SA children, emphasizing the maintenance of healthy diets with appropriate energy intakes coupled with sustained physical activity through childhood and beyond, will be particularly important.

Acknowledgements We thank the CHASE Study Team and all participating schools, pupils and parents. This research was supported by grants from the British Heart Foundation (PG/15/19/31336 and FS/17/ 76/33286). Diabetes prevention research at St George's, University of London, is supported by the National Institute of Health Research (NIHR) Collaboration for Leadership in Applied Health Research and Care South London (NIHR CLAHRC-2013-10022). The CHASE Study was funded by the Wellcome Trust (grant 068362/Z/02/Z). The views expressed in this paper are those of the authors and not necessarily those of the funding agencies, the National Health Service, the NIHR or the Department of Health. Dr Nightingale is supported by the Wellcome Trust Institutional Strategic Support Fund (204809/Z/16/Z) awarded to St George's, University of London.

Author contributions Study concept-MTH, CMN, PHW, CGO, ARR, DGC. Raising grant funds-CMN, PHW, CGO, ARR, DGC. Data collection-PHW, DGC, CGO. Data analysis-MTH, CMN, ARR. Data interpretation-All authors. Drafting manuscript-MTH, PHW, CMN. Critical evaluation and revision of manuscript-All authors. 


\section{Compliance with ethical standards}

Conflict of interest The authors declare that they have no conflict of interest.

Open Access This article is licensed under a Creative Commons Attribution 4.0 International License, which permits use, sharing, adaptation, distribution and reproduction in any medium or format, as long as you give appropriate credit to the original author(s) and the source, provide a link to the Creative Commons license, and indicate if changes were made. The images or other third party material in this article are included in the article's Creative Commons license, unless indicated otherwise in a credit line to the material. If material is not included in the article's Creative Commons license and your intended use is not permitted by statutory regulation or exceeds the permitted use, you will need to obtain permission directly from the copyright holder. To view a copy of this license, visit http://creativecommons. org/licenses/by/4.0/.

\section{References}

1. World Health Organisation. Appropriate body-mass index for Asian populations and its implications for policy and intervention strategies. Lancet. 2004;363:157-63.

2. Gray LJ, Yates T, Davies MJ, Brady E, Webb DR, Sattar N, et al. Defining obesity cut-off points for migrant South Asians. PLoS ONE. 2011;6:e26464.

3. Ntuk UE, Gill JM, Mackay DF, Sattar N, Pell JP. Ethnic-specific obesity cutoffs for diabetes risk: cross-sectional study of 490,288 UK biobank participants. Diabetes Care. 2014;37:2500-7.

4. Tillin T, Sattar N, Godsland IF, Hughes AD, Chaturvedi N, Forouhi NG. Ethnicity-specific obesity cut-points in the development of Type 2 diabetes-a prospective study including three ethnic groups in the United Kingdom. Diabet Med. 2015;32:22634.

5. National Institute for Health and Care Excellence. Obesity: identification, assessment and management of overweight and obesity in children, young people and adults. National Clinical Guideline Centre; 2014. https://www.nice.org.uk/guidance/cg189/evidence/ obesity-update-full-guideline-pdf-193342429. Accessed 26 March 2018.

6. Song Y, Manson JE, Tinker L, Howard BV, Kuller LH, Nathan L, et al. Insulin sensitivity and insulin secretion determined by homeostasis model assessment (HOMA) and risk of diabetes in a multiethnic cohort of women: the Women's Health Initiative Observational Study. Diabetes Care. 2007;30:1747-52.

7. Haffner SM, Kennedy E, Gonzalez C, Stern MP, Miettinen H. A prospective analysis of the HOMA model. The Mexico City Diabetes Study. Diabetes Care. 1996;19:1138-41.

8. Morrison JA, Glueck CJ, Horn PS, Schreiber GB, Wang P. Preteen insulin resistance predicts weight gain, impaired fasting glucose, and type 2 diabetes at age $18-19$ y: a $10-\mathrm{y}$ prospective study of black and white girls. Am J Clin Nutr. 2008;88:778-88.

9. Whincup PH, Nightingale CM, Owen CG, Rudnicka AR, Gibb I, McKay CM, et al. Early emergence of ethnic differences in type 2 diabetes precursors in the UK: the Child Heart and Health Study in England (CHASE Study). PLoS Med. 2010;7:e1000263.

10. Tanner JM. Growth at adolescence. 1st ed. Oxford: Blackwell Scientific; 1962.

11. Levy JC, Matthews DR, Hermans MP. Correct homeostasis model assessment (HOMA) evaluation uses the computer program. Diabetes Care. 1998;21:2191-2.

12. Cole TJ, Freeman JV, Preece MA. Body mass index reference curves for the UK, 1990. Arch Dis Child. 1995;73:25-9.

13. Hudda MT, Nightingale CM, Donin AS, Fewtrell MS, Haroun D, Lum $\mathrm{S}$, et al. Body mass index adjustments to increase the validity of body fatness assessment in UK Black African and South Asian children. Int J Obes. 2017;41:1048-1055.

14. de Wilde JA, van Dommelen P, Middelkoop BJ. Appropriate body mass index cut-offs to determine thinness, overweight and obesity in South Asian children in the Netherlands. PLoS ONE. 2013;8:e82822.

15. Duncan JS, Duncan EK, Schofield G. Ethnic-specific body mass index cut-off points for overweight and obesity in girls. $\mathrm{N} Z \mathrm{Z}$ Med J. 2010;123:22-9. 